Brit. J. prev. soc. Med. (1975), 29, 178-181

\title{
A study of breast cancer in Irish women
}

\author{
BERNADETTE A. HERITY,1 M. J. O'HALLORAN,2 G. J. BOURKE, ${ }^{1}$ AND K. WILSON-DA
Department of Social and Preventive Medicine, University College, Dublin ${ }^{1}$, St Luke's Hospital, Dublin ${ }^{2}$ \\ Social Statistics Laboratory, University of Strathclyde, Scotland ${ }^{3}$
}

\begin{abstract}
Herity, B. A., O'Halloran, M. J., Bourke, G. J., and Wilson-Davis, K. (1975). British Journal of Preventive and Social Medicine, 29, 178-181. A study of breast cancer in Irish women. In a study of 100 women with breast cancer and 200 unaffected women the epidemiological characteristic of breast cancer most commonly described-namely, an excess of nonparous women among cases when compared with controls, was not observed. It is suggested that two factors, a dearth of first births born to mothers under 20 years of age and an unusually high proportion of first births when aged 30 years or more, are responsible for this finding. No association was found between breast cancer and socioeconomic status, marital status, age at marriage, age at first pregnancy, parity, or age at menarche. Significant associations with breast cancer included age at natural menopause, hysterectomy, and breast trauma. These findings are discussed.
\end{abstract}

One of the most consistent observations in studies of breast cancer in women has been the association between high parity and a reduced risk of developing the disease, and the interpretation of this epidemiological characteristic has been that pregnancy or a concomitant of pregnancy affords protection against breast cancer, and that the amount of protection is related to the total number of pregnancies. A recent collaborative international study has further elucidated the nature of the protective effect of pregnancy (Salber, Trichopoulos, and MacMahon, 1969; Valaoras et al., 1969; Lowe and MacMahon, 1970; MacMahon et al., 1970b; Yuasa and MacMahon, 1970). Analyses of data from all centres included in the study have shown a decreased risk of breast cancer strongly associated with age at first pregnancy. The association with high parity appears to reflect only an early start to childbearing, those women who had early first pregnancies tended ultimately to have large families. Since no study of the epidemiological features of breast cancer in the Republic of Ireland had previously been done, and in the light of the unusual demographic characteristics of late marriage and late first pregnancies associated with high fertility rates, this study was carried out in 1972-73.

\section{METHOD}

Altogether 100 breast cancer cases selected randomly from the outpatient register of St Luke's
Hospital, Dublin, were compared with a presenti为过 sample of 200 controls attending the fracture clinics of St Vincent's and the Mater Misericordiae hospitals in Dublin during the same period. Breast $\overrightarrow{0}$ cancer patients aged under 35 years were matched with controls who were within two years of the same age, and where cases were over 35 years of age controls were required to be over 35 years, but age-matching was not considered necessary. Cases and controls were interviewed by one of us $(\mathrm{BH})$ 을

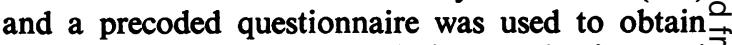
detailed information of marital, reproductive, and family history, history of previous illness, and smoking habits. The height of cases and controls was measured and controls were examined to exclude the possibility of their having breast cancer.

\section{RESULTS}

\section{Age and Socioeconomic Status}

Although age-matching of controls was carried $\stackrel{\circ}{\triangle}$ out only for breast cancer patients who were aged $?$ under 35 years, the overall age distributions of cases and controls were similar, the mean age of both $N$ groups being 57.3 years. There were no significant ${ }_{N}$ differences in socioeconomic status as measured by mean duration of schooling (cases 10.3 years; $\sigma$ controls 10.5 years; $P=0.34$ ), by father's occupation $(P>0 \cdot 10)$, and by husband's occupation $(P>0 \cdot 10)$ in the case of the evermarried women. 


\section{Marital Status}

There was no significant difference between cases and controls for marital status (Table I). Twentyfour cases $(24.0 \%)$ and 54 controls $(27.0 \%)$ had never married, and none of the single women at interview gave a history of pregnancy.

TABLE I

MARITAL STATUS

\begin{tabular}{l|c|c|c|c|c}
\hline Women & Single & Married & Widowed & Separated & Total \\
\hline Cases & $24(24 \cdot 0)$ & $49(49 \cdot 0)$ & $24(24 \cdot 0)$ & $3(3 \cdot 0)$ & $100(100)$ \\
Controls & $54(27 \cdot 0)$ & $92(46 \cdot 0)$ & $51(25 \cdot 5)$ & $3(1 \cdot 5)$ & $200(100)$ \\
\hline
\end{tabular}

$\chi^{2}=0.3584, \mathrm{df}=2,0.90>p>0.80$

Percentages are given in parentheses

\section{Age at Marriage and at First Pregnancy}

The mean ages at marriage for cases and controls were $28 \cdot 1$ and 26.9 years respectively $(P=0 \cdot 22)$, and the mean ages at first pregnancy were $28 \cdot 2$ and $27 \cdot 4(P=0 \cdot 36)$. It will be seen (Table II) that only three cases $(4 \cdot 6 \%)$ and four controls $(3 \cdot 3 \%)$ had their first pregnancies when under 20 years of age, and a high proportion of both cases $(41.6 \%)$ and controls $(32.5 \%)$ had their first pregnancies at the age of 30 years or later.

TABLE II

AGE IN YEARS AT FIRST PREGNANCY

\begin{tabular}{l|c|c|c|c|c|c}
\hline Women & 20 & $20-24$ & $25-29$ & $30-34$ & $35+$ & Total \\
\hline Cases & 3 & 17 & 18 & 17 & 10 & $65^{*}$ \\
Controls & $(4 \cdot 6)$ & $(26 \cdot 2)$ & $(27 \cdot 6)$ & $(26 \cdot 2)$ & $(15 \cdot 4)$ & $(100)$ \\
& 4 & 37 & 42 & 29 & 11 & $123 *$ \\
& $(3 \cdot 3)$ & $(30 \cdot 1)$ & $(34 \cdot 1)$ & $(23 \cdot 6)$ & $(8 \cdot 9)$ & $(100)$ \\
\hline
\end{tabular}

* 35 cases and 77 controls had never been pregnant $x^{2}=2 \cdot 1739$, df $=3,0.60>p>0.50$

Percentages are given in parentheses

\section{Parity and Lactation Experience}

Cases and controls did not differ significantly in total parity (Table III), nor were differences observed in their abortion or stillbirth experiences.

\section{TABLE III}

PARITY OF MARRIED WOMEN

\begin{tabular}{l|c|c|c|c|c}
\hline Women & 0 & $1-4$ & $5-8$ & $9+$ & Total \\
\hline Cases & $11(14 \cdot 5)$ & $34(44 \cdot 7)$ & $21(27 \cdot 6)$ & $10(13 \cdot 2)$ & $76(100)$ \\
Controls & $23(15 \cdot 8)$ & $60(41 \cdot 1)$ & $48(32 \cdot 9)$ & $15(10 \cdot 2)$ & $146(100)$ \\
\hline \multicolumn{5}{c}{$\begin{array}{l}\chi_{2}^{2}=0 \cdot 9828, \text { df }=3, \quad 0 \cdot 90>\text { P }>0 \cdot 80 \\
\text { Percentages are given in parentheses }\end{array}$}
\end{tabular}

In the light of information from other studies a detailed history of lactation experience was not undertaken but women who had liveborn babies were asked if they had breastfed these babies. Altogether 49 cases $(75.4 \%)$ and 86 controls $(69.9 \%)$ had had some breastfeeding experience.

\section{Menstrual History}

The mean age at menarche for cases was 13.9 years and for controls 14.0 years $(P=0.59)$. There was a trend for more cases than controls to report age at menarche as 12 years or younger, but it is not significant $(P=0 \cdot 50)$.

Age at natural menopause is shown (Table IV) and was significantly later for cases than controls. Cases who had an artificial menopause induced as part of their treatment for breast cancer are not included in the total.

TABLE IV

AGE IN YEARS AT NATURAL MENOPAUSE

\begin{tabular}{l|c|c|c}
\hline \multicolumn{1}{c|}{ Women } & $\overline{\mathrm{x}}$ & SD & $\mathrm{N}$ \\
\hline Cases & 47.33 & 4.21 & $57^{*}$ \\
Controls & 45.97 & 4.57 & $128^{*}$ \\
\hline
\end{tabular}

*43 cases and 72 controls had not yet reached the menopause or had had an artificial menopause $Z=1.9753 \quad P<0.05$

\section{History of Previous Illness}

History of previous hysterectomy was significantly more frequent for controls than cases (Table V).

TABLE V

HISTORY OF HYSTERECTOMY

\begin{tabular}{l|c|c|c}
\hline \multirow{2}{*}{ Women } & \multicolumn{2}{|c|}{ Hysterectomy } & \multirow{2}{*}{ Total } \\
\cline { 2 - 4 } & Yes & No & 100 \\
Cases & 4 & 96 & $(100)$ \\
\multirow{3}{*}{ Controls } & $(4 \cdot 0)$ & $(96 \cdot 0)$ & 200 \\
& 25 & 175 & $(100)$ \\
\hline
\end{tabular}

$\chi^{2}$ with Yates correction $=4.8248$, df $=1,0.05>P>0.02$ Percentages are given in parentheses

A significantly greater number of cases $\left(\chi^{2}=14 \cdot 612, \mathrm{df}=1, P<0.005\right)$ gave a history of previous breast trauma. There was no association with thyroid conditions, diabetes mellitus, uterine fibroids, ovarian disease, smoking history, or previous $x$-ray experience. 


\section{Miscellaneous}

There was no difference in height between cases and controls $(P=0 \cdot 61)$. The cancer occurred more frequently in the left than in the right breast but the difference was not significant $(P=0 \cdot 09)$.

\section{Discussion}

The study of breast cancer in Irish women has produced some unexpected results. The association usually observed between higher socioeconomic status and the development of breast cancer was not present (Stocks, 1955, 1957; Salber et al., 1969; Valaoras et al., 1969; Lowe and MacMahon, 1970; MacMahon et al., 1970b; Yuasa and MacMahon, 1970). However this result was influenced by the method of selection inherent in interviewing patients attending hospital outpatient departments, since the system of medical care which operates in the Republic of Ireland whereby some persons in the higher social groups are treated as private patients and therefore are not accessible to hospital research projects, eliminates to some extent differences in socioeconomic status.

Interesting findings were the absence of significant differences between cases and controls for marital status and age at first pregnancy. In many studies an excess of single women among the cases has been a predominant feature, and in the international study only the data from Slovenia (Ravnihar, MacMahon, and Lindtner, 1971) did not show significant differences in marital status between cases and controls. However it is suggested (MacMahon et al., 1970a) that the fact that in Slovenia $25 \%$ of the single women reported having had one or more pregnancies might account for some of the discrepancy between the data for Slovenia and the other centres. In the present study mean age at first pregnancy was $28 \cdot 2$ years for cases and 27.4 years for controls, and only three cases $(4 \cdot 6 \%)$ and four controls $(3.3 \%)$ had their first pregnancies when under 20 years of age. Even more striking was the number of cases $27(41 \cdot 6 \%)$ and controls $40(32 \cdot 5 \%)$ who were first pregnant when 30 years or older. In the international study (MacMahon et al., 1970b) more women in Athens and Slovenia than in other centres had their first pregnancies when they were 30 years and older $(19.7 \%$ of cases and $15.0 \%$ of controls respectively) and it was shown that the risk of those first pregnant between the ages of 30 and 34 years approaches that of the nulliparous, and that first pregnancies at 35 years and older actually increase the risk relative to the nulliparous. It is suggested that the demographic characteristic of late first pregnancies among married women in this study 0 accounts for the unexpected excess of those women among the cases.

Another constant finding in studies of breast $\stackrel{\mathbb{P}}{?}$ cancer epidemiology has been that controls are of $\vec{F}$ higher parity than cases, but in the present study significant differences were not seen. It has been shown, however, that the association of reduced $\frac{\bar{\sigma}}{\bar{c}}$ risk of breast cancer with high parity is dependent $\frac{\omega}{\sigma}$ on the fact that those who have early first preg- $\propto$ nancies tend ultimately to have large families, and $\%$ that pregnancies when over the age of 25 do not $\vec{\circ}$ reduce the risk (MacMahon et al., 1970b). The result of the present study is interesting as it adds to $\vec{\omega}$ the evidence that high parity is not per se a pro- ?

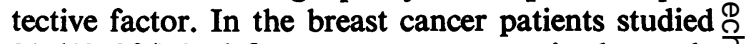
$31(40.8 \%)$ had five or more pregnancies but only three $(4.6 \%)$ had had first pregnancies when under 20 years, so the reduction in risk is minimal in these women in spite of their high parity.

There was a trend for more cases than controls 응 to report age of menarche at 12 years and youngep but this was not significant. However, the proble $(\overrightarrow{)}$ of recall of age of menarche was noticeable $q 4 \mathbb{O}$ interview in both cases and controls. In contras $\frac{\mathbb{D}}{3}$ age at natural menopause was remembered withoet difficulty by the majority of women and was signi $\frac{\mathbb{D}}{-}$ ficantly later for cases than controls. This is $\overrightarrow{0}$ agreement with data from previous studies (Olch, जे 1937; Lilienfeld, 1956; MacMahon and Feinleib; 1960; Wynder, Bross, and Hirayama, 1960; Hirayama and Wynder, 1962; Salber et al., 1969; Ravnihar et al., 1971; Trichopoulos, MacMahon, and Cole, 1972). A previous hysterectomy was found significantly more often in controls than in cases. This epidemiological characteristic has also been noted previously (Lane-Claypon, 1926; MacMahon and Feinleib, 1960; Hirayama and Wynder, 1962; Kaplan and Acheson, 1966; Feinleib, 1968; Salber et al., 1969).

Significantly greater numbers of cases gave a ? history of earlier trauma to the breast. Injuries described included trauma from a sharp edge of furniture, from a garden spade while digging, and $\frac{\rho}{\gamma}$ from a door handle in a car crash, but it is recognized that breast cancer patients are more likely to recall, $\frac{}{工}$ and perhaps exaggerate, any trauma to the breast $\frac{D}{O}$ which they may have received.

The demographic characteristics which produced $N$ the unusual features of a late start to pregnancy associated with high fertility have undergone change 0 in the Republic of Ireland in recent years. This is $\omega$ because of a drop in emigration resulting in an increase of persons of marriageable age, and an increase of $50 \%$ in the marriage rate in 10 years. 
During the mid-1960's there was an overall decline in fertility closely associated with age. There was no change in the fertility rate for women of under 22 years, but it fell by $7 \%, 15 \%$, and $45 \%$ respectively in the 22 to 25,26 to 39 , and $40+$ age-groups (FitzGerald, 1974). Since 1971 there has been a small but definite decline in the birth rate, a gradually increasing marriage rate, and an earlier age at marriage. What effect this demographic transformation will have on breast cancer epidemiology in the Republic of Ireland can only be surmised, but earlier age of marriage, provided it remains associated with earlier age at first pregnancy, should produce a decrease in parous women relative to non-parous among breast cancer patients, and perhaps also a decrease in breast cancer.

We are indebted to the Directors of St Luke's Hospital, Dublin, for a grant for this study from the St Luke's Cancer Research Fund, and to the staff of the Outpatients' and Medical Records' departments of this hospital for their courtesy and assistance. Our thanks are also due to $\mathrm{Mr} \mathrm{J}$. Gallagher and $\mathrm{Mr} \mathrm{J}$. Sheehan (St Vincent's Hospital, Elm Park, Dublin) and to Mr P. MacAuley and Mr N. Mulvihill (Mater Misericordiae Hospital, Dublin) Consultant Orthopaedic Surgeons, who gave us permission to interview patients (controls) under their care.

Requests for reprints: B. A. Herity, Department of Social and Preventive Medicine, University College, Dublin.

\section{REFERENCES}

Feinleib, M. (1968). Breast cancer and artificial menopause: A cohort study. J. nat. Cancer Inst., 41, 315.

FitzGerald, G. (1974). Demographic developments-II. The Irish Times, April 24, p. 13.

Hirayama, T. and Wynder, E. L. (1962). A study of the epidemiology of cancer of the breast. II. The influence of hysterectomy. Cancer, 15, 52.

Kaplan, S. D. and Acheson, R. M. (1966). A single etiological hypothesis for breast cancer? J. chron. Dis., 19, 1221.
Lane-Claypon, J. E. (1926). A Further Report on Cancer of the Breast with Special Reference to its Associated Antecedent Conditions. Reports on Public Health and Medical Subjects, No. 32. HMSO, London.

LILIENFELD, A. M. (1956). The relationship of cancer of the female breast to artificial menopause and marital status. Cancer, 9, 927.

Lowe, C. R. and MacMahon, B. (1970). Breast cancer and reproductive history of women in south Wales. Lancet, 1, 153.

Macmahon, B., Cole, P., Lin, T. M., Lowe, C. R., Mirra, A. P., Ravnihar, B., Salber, E. J., Valaoras, V. G., and YuASA, S. (1970a). Lactation and cancer of the breast. Bull. Wld Hlth Org., 42, 185.

- and FeINLEIB, M. (1960). Breast cancer in relation to nursing and menopausal history. $J$. nat. Cancer Inst., 24, 733.

- Lin, T. M., Lowe, C. R., Mirra, A. P., Ravnihar, B., Salber, E. J., Trichopoulos, D., Valaoras, V. G., and YuASA, S. (1970b). Age at first birth and breast cancer risk. Bull. Wld Hlth Org., 43, 209.

OLCH, I. Y. (1937). Menopausal age in women with cancer of breast. Amer. J. Cancer, 30, 563.

RAVNiHAR, B., MACMAHON, B., and LindTNER, J. (1971). Epidemiologic features of breast cancer in Slovenia, 1965-67. Europ. J. Cancer, 7, 295.

Salber, E. J., Trichopoulos, D., and MacMahon, B. (1969). Lactation and reproductive histories of breast cancer patients in Boston, 1965-67. J. nat. Cancer Inst., 43, 1013.

STOcKs, P. (1955). Social status in relation to carcinoma of breast. Schweiz. Z. allg. Path., 18, 706.

(1957). The epidemiology of carcinoma of the breast. Practitioner, 179, 233.

Trichopoulos, D., MacMahon, B., and Cole, P.(1972). Menopause and breast cancer risk. J. nat. Cancer Inst., 48, 605.

Valaoras, V. G., MacMahon, B., Trichopoulos, D., and Polychronopoulou, A. (1969). Lactation and reproductive histories of breast cancer patients in Greater Athens, 1965-67. Int. J. Cancer, 4, 350.

Wynder, E. L., Bross, I. J., and Hirayama, T. (1960). A study of the epidemiology of cancer of the breast. Cancer, 13, 559.

Yuasa, S. and MacMahon, B. (1970). Lactation and reproductive histories of breast cancer patients in Tokyo, Japan. Bull. Wld Hlth Org., 43, 195. 